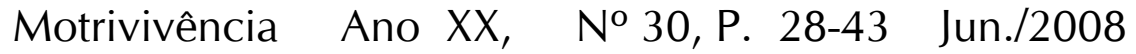

\title{
Futebol Feminino e as Barreiras do Sexismo nas Escolas: reflexões acerca da invisibilidade
}

\author{
Cássia Cristina Furlan? \\ Patrícia Lessa dos Santos²
}

\begin{abstract}
Resumo Abstract
A pesquisa teve por objetivo observar jogadoras de futebol e suas autorrepresentações, como elas veem a participação das mulheres no futebol e se as escolas incentivam a prática dessa atividade, verificando questões de gênero. Apresenta também análise das interfaces e desdobramentos dessa prática no interior da escola e da educação física escolar. Com metodologia qualitativa, foram realizadas entrevistas com acadêmicas de educação física e atletas. Verificou-se que ainda estão presentes preconceitos em relação ao futsal feminino, e que as condições de acesso e participação nas práticas corporais e esportivas ainda favorecem o universo masculino.

The research aimed to observe soccer players and their self-representations, how they see women's participation in football and if schools encourage the practice of this activity, noting gender issues. It also presents analysis of interfaces and developments of practice within the school and school physical education. In qualitative methodology, interviews were conducted with academic and physical education athletes. It was found that there are prejudices about women's soccer, and that the conditions of access and participation in sports and bodily practices still favor the male universe.
\end{abstract}

Palavras-chave: Futebol feminino; Gênero; Escola; Educação física escolar.

Keywords: Women's soccer; Gender; School; school physical education.

1 Universidade Estadual de Maringá. Contato: cassia.furlan@hotmail.com

2 Universidade Estadual de Maringá. Contato: mafalda_cat@yahoo.com.br 


\section{Introdução}

Nas discussões acerca da opressão sofrida pelas mulheres, a construção dos papéis femininos e masculinos, enfatizando o caráter social, remete-nos a uma reflexão sobre as questões de gênero. A igualdade entre homens e mulheres inclui e depende do reconhecimento das diferenças. A diferença entre os gêneros perpassa a construção sócio-cultural dos costumes, condutas e normas do ser humano, considerando-se a dimensão biológica e a cultural.

Com esta pesquisa, pretende-se articular a produção teórica sobre estudos de gênero e a construção de conceitos de feminino e masculino, procurando relacionálos com a representação que se tem sobre o tema nas escolas, usando como dados para análise a pesquisa sobre futebol feminino. Ainda hoje as mulheres sofrem preconceito na prática desse esporte. Busca-se compreender a razão pela qual esse esporte se iniciou tardiamente no país entre as mulheres e no âmbito escolar, e reforçar a importância de romper as relações que se construíram no decorrer da história.

O estudo se justifica por buscar um debate maior sobre a construção do sexismo nas escolas, no intuito de superar essas relações sociais de poder, procurando a construção de uma sociedade igualitária. Procurou-se assim desvendar e explicitar as discriminações e preconceitos associados à questão de gênero, especificamente a partir do futebol feminino, com o propósito de combater relações autoritárias, questionar a rigidez dos padrões de conduta estabelecidos para homens e mulheres e apontar para a sua transformação. Mais especificamente, a pesquisa teve por objetivo observar jogadoras de futebol e suas autorrepresentações, como elas veem a participação das mulheres no futebol e se as escolas incentivam a prática dessa atividade, verificando questões de gênero. Apresenta também análise das interfaces e desdobramentos dessa prática no interior da escola e da educação física escolar. Em metodologia qualitativa, realizouse uma pesquisa de campo, em que se procurou o aprofundamento de uma realidade específica. $\mathrm{Na}$ primeira parte, foram realizadas observações e entrevistas, focadas em quinze meninas de 11 a 17 anos (as quais serão nomeadas no decorrer da pesquisa de jogadora $A$, jogadora $B$, etc.), que jogam futsal e estudam no Colégio Estadual Zulmira Marchesi da Silva, na cidade de Cornélio Procópio. Na segunda parte, realizaram-se entrevistas com duas acadêmicas ( $A$ e B) do curso de educação física, da Universidade 
Estadual de Maringá; elas já jogaram futsal e vêm se empenhando para dar início a times de futsal feminino dentro das escolas de Maringá.

A pesquisa fundamenta-se nas teorias feministas (HARGREAVES, 1994; SWAIN, 2009) que partem da perspectiva teórico-metodológica não neutra. Como aponta Swain (2009), o feminismo como movimento político transformador interroga e desconstrói a naturalização dos corpos em papéis e práticas sociais, e, como conhecimento crítico, interroga os discursos sociais, em seus desdobramentos de etnia, raça, classe, gênero e sexualidade, além de interrogar o próprio sexo biológico na constituição do sujeito "mulher". O sujeito do feminismo produz-se em um movimento complexo e dinâmico, na análise das engrenagens de constituição do corpo/sujeito/sexo, na experiência das práticas sociais generizadas enquanto mulher - e na crítica ao quadro epistemológico no qual se insere seu próprio discurso.

A produção do conhecimento das relações de gênero na educação física ainda encontra muita resistência, embora no Brasil já existam referências na discussão (GOELLNER, 2001, 2005b, 2007a; VOTRE, 1996; LOURO, 1995, 2007a, 2007b). A educação física prendeu-se muito nos paradigmas modernos - positivismo e marxismo
-, e nesse sentido, não conseguiu acompanhar as discussões sobre raça, gênero, sexualidade, diversidade, haja vista que essas questões são pouco questionadas naquelas teorias. A opção pelo campo teórico feminista e dos estudos de gênero se faz por duas questões: 1) a importância dada ao estudo do corpo e da sexualidade; 2) pelo seu ponto de vista sobre a ciência, o de que a ciência é apenas um dos modos de ver o mundo, e ela pode e deve ser questionada (SWAIN, 2009).

\section{História das mulheres e estu- dos de gênero nas epistemo- logias feministas}

No Brasil, a situação das mulheres nas relações de gênero é marcada por espaços de contradições, ideologias e discriminações sociais que as colocam no papel de "sexo frágil". Na trajetória das mulheres, pode-se perceber a constante quebra de regras e normas que impediam o exercício de expressão, confinando-as à esfera doméstica: cuidar da casa, dos filhos, procriar, e outros. Numa concepção tradicional de educação, passada de geração em geração, as mulheres não podiam expressar nenhuma de suas revoltas (TOJAL, 2003). Entretanto, discutir o espaço conquistado pelas mulheres e as relações de gênero continua sendo, sem dúvida, um 
grande desafio, pois, apesar das grandes reivindicações feministas, há muitas barreiras e preconceitos, discriminação e opressão que inviabilizam a real liberdade das mulheres. Importa reverter esse quadro de exclusão que ainda permanece na sociedade brasileira.

Goellner (2007b, p. 15) afirma que:

Pensando no que comumente tem sido denominado de "história das mulheres" é possível vislumbrar um horizonte pleno de multiplicidades, de interpretações, de olhares, de formas de narrar suas trajetórias, histórias de vida, biografias, ações políticas, culturais, esportivas, entre outras. Essa multiplicidade advém tanto das configurações teóricas e metodológicas adotadas pelos(as) historiadores(as), quanto das questões afetas à compreensão que se tem acerca do objeto específico de investigação, ou seja, sobre próprias mulheres. Isso significa afirmar que na historiografia sobre as mulheres tanto se pode encontrar abordagens que tratam das mulheres como um bloco uníssono quanto aquelas que se analisam ressaltando suas particularidades e diferenças.

Nesse sentido, é importante o entrelaçamento entre história e estudos de gênero nas epistemologias feministas, conferindo a emergência de diferentes práticas discursivas permitindo a visibilidade das mulheres como sujeitos históricos. A epistemologia feminista interroga a ciência, cria o conceito de gênero para pensar as relações sociais e abre o campo para pesquisas históricas onde o sujeito feminino não está invisibilizado, ignorado (GOELLNER, 2007b).

Segundo Scott (1988), o gênero é um elemento constitutivo das relações sociais, sendo fundado nas diferenças percebidas entre os sexos, comportando como primeiro significado as relações de poder. É no campo social que se constroem e se reproduzem as relações desiguais entre os sujeitos. As justificativas para as desigualdades precisariam ser buscadas nos arranjos sociais, na história, nas condições de acesso aos recursos da sociedade, nas formas de representação e não nas diferenças biológicas.

Para Louro (1995, p.104105),

Ao introduzir a teoria pós-estruturalista na história das muIheres/de gênero, Scott assuntou os fundamentos para uma reinterpretação crítica de conceitos tais como experiência, agência e identidade e colocou o gênero no coração das nascentes discussões históricas do 
pós-estruturalismo. Ainda que a história das mulheres/de gênero preparasse o terreno em muitos aspectos para a virada linguística, as respostas frequentemente cáusticas ao desafio de Scott deixam claro que este é também um campo no qual os riscos do debate são particularmente altos.

O gênero, ao enfatizar o caráter fundamentalmente social das divisões baseadas no sexo, possibilita perceber as representações e apresentações das diferenças sexuais. Imbricadas nas diferenças biológicas existentes entre homens e mulheres estão outras social e culturalmente construídas. Nesse sentido, Louro (2007b) afirma que a segregação social e política a que as mulheres foram historicamente conduzidas teve como consequência a sua ampla invisibilidade como sujeito. O saber reconhecia o universal como masculino; o feminino, quando considerado, constituía o exemplo do desviante, reafirmando o senso comum de inferioridade e subordinação do sexo feminino. "O argumento de que os homens e muIheres são biologicamente distintos e que as relações entre ambos decorrem dessa distinção" (LOURO, 2007a, p.20) serviu e serve para justificar a desigualdade social.

Para Meyer (2003, p.16), “as abordagens feministas pós-estruturalistas se afastam daquelas vertentes que tratam o corpo como uma entidade biológica universal [...] para teorizá-lo como um constructo sociocultural e linguístico". E é nesse sentido que os estudos feministas, ou epistemologia feminista (SWAIN, 2009), que englobam o conceito de gênero, são fundamentais em nossa pesquisa. A discriminação da muIher começa cedo, no momento do nascimento ou mesmo antes, pois quando meninas e meninos chegam à escola já têm interiorizada a maioria dos padrões de conduta discriminatória.

\section{O ambiente escolar e a educa- ção física: a prática do futebol feminino e o preconceito}

O ambiente escolar, desde o seu início, produziu distinções e desigualdades, a escola se incumbiu de separar os sujeitos, através de múltiplos mecanismos de classificação, ordenamento e hierarquização. No entender de Pereira (2004), a escola, em seu cotidiano, como instituição detentora das funções educacionais e de formação social, produz e reproduz ações que separam e demarcam o que é considerado socialmente como pertencente ao mundo feminino e ao mundo masculino.

Altmann (1998 apud DARIDO, 2002) ressalta que o esporte, como expressão do masculino, pode ser observado pelas linguagens que 
ocorrem na escola, que não apenas reproduzem uma determinada imagem masculina, mas a constrói. $O$ esporte se associa a masculinidade pautada na imagem de um homem forte, violento e vitorioso. Altmann (1998) explica que a associação do esporte à masculinidade varia de acordo com a modalidade, e na escola o futebol é considerado o mais masculino dos esportes. Uma das entrevistadas, acadêmica de educação física, quando foi questionada se ela considerava esportes como sendo masculinos e femininos, disse: "Não que pra mim seja assim, mas pra sociedade sim. Por exemplo, deixa eu pensar... Boxe para homem e ginástica para muIher, alguns esportes exigem mais força e outros mais sensibilidade, daí a visão preconceituosa das pessoas de acharem que alguns são somente pra homens e outros pra mulheres. Mas os dois sexos podem fazer qualquer tipo de esporte, independente se exigem força ou mais sensibilidade"(Acadêmica B).

Portanto, o processo pela autonomia social e inserção da mulher no universo dos esportes tem sido bastante conturbado, marcado por barreiras e dificuldades, algumas já vencidas e outras por serem superadas.

Os estereótipos biológicos que tinham por base uma análise anatomofisiológica e sempre colocavam os atletas do sexo masculino com maiores possibilidades de sucesso - acabaram reforçando preconceitos e, num primeiro momento, dificultando a jornada das mulheres pelo mundo dos esportes (SIMÕES, 2003, p.17).

Louro (2007a, p.72-73) nos lembra que a constituição da identidade de gênero muitas vezes é feita por meios implícitos,

Nas aulas de educação física esse processo é, geralmente, mais explícito e evidente. Ainda que várias escolas e professores/as venham trabalhando em regime de co-educação, a educação física parece ser a área onde as resistências ao trabalho integrado persistem, ou melhor, onde as resistências provavelmente se renovam, a partir de outras argumentações ou de novas teorizações.

No momento de introdução dos esportes na educação física escolar brasileira, as meninas foram tidas como seres frágeis e dóceis, e os meninos dotados de força, dominação e poder, marcas que reiteram a diferença de gênero. A construção das imagens de feminilidade aparece inserida na educação física em diferentes espaços e tempos, formas e estratégias diversas. 
Tais imagens fazem parte de um contexto sócio-cultural para o qual os papéis masculinos e femininos estão designados.

Se é conformação anatômica dos sujeitos aquilo que os define, dentro dessa perspectiva, nada mais "natural" que recomendar aos homens e mulheres diferentes possibilidades de movimentação. A eles a aventura, a potência, o desafio, a força; a elas, a aventura comedida, a potência controlada, a força mensurada, o desafio ameno. Para as mulheres, em grande medida, é incentivado viver o espetáculo esportivo desde que não deixe de lado, por exemplo, a graciosidade, a delicadeza e a beleza, atributos colados a uma suposta "essência feminina". Argumentos como estes operam como mecanismos de exclusão e inclusão em diferentes modalidades esportivas, posicionam as mulheres, demarcam seus espaços de sociabilidade, pois insistem em afirmar que determinadas atividades não são apropriadas aos seus corpos vistos, grosso modo, como de natureza mais frágil que os corpos dos homens (GOELLNER, 2007a, p. 184-185).

O esporte e a educação física têm sido campos férteis de reprodução do sexismo e do machismo. Não é recente o fato de que as mulheres se esforçam e enfrentam desafios para se firmar num campo marcadamente androcêntrico: o esporte. Culturalmente, o esporte tem se apresentado como uma prática onde a masculinidade se comprova, na qual se aprende a valorizar o homem e a desvalorizar a mulher (LESSA, 2005). Nas aulas de educação física, os atos de exclusão se reforçam na medida em que o conteúdo central é o esporte, pois sendo conteúdo generificado e generificador, já traz em seu contexto histórico a problematização de gênero reafirmando os preconceitos estabelecidos em outros tempos, sobre a participação feminina nessas aulas.

A igualdade desejada nas aulas de educação física não deve ser uma comparação entre meninos e meninas; o importante nesse processo é valorizar a diferença e a contribuição individual para todos os meninos e meninas, proporcionando atividades que possam ser praticadas por todos, contribuindo para a construção do ser social.

Para Altmann (1999), quando meninas jogam contra meninos, ao invés de estes sentirem-se desafiados, sentem-se ameaçados em sua masculinidade, por medo de serem vencidos, pois as meninas podem, em algum momento, superar as expectativas e apresentarem-se com 
grande habilidade para os esportes. Nesse sentido, a afirmação de uma das entrevistadas confirma o que a autora expõe: "no colégio, os meninos não deixam nós jogarmos com eles por sermos mulheres" (Jogadora 5), enfatizando a insegurança dos meninos quanto à superação por parte das meninas.

A mesma autora reconhece que:

Separar meninos e meninas nas aulas é estabelecer uma divisão polarizada entre gêneros; é exagerar uma generificação das diferenças entre as pessoas, desconsiderando variações no gênero e considerando apenas diferenças de gênero como importantes numa aula; é tornar as fronteiras das divisões de gênero mais rígidas do que de fato são, e negar aos meninos e meninas a possibilidade de cruzálas; é furtar-lhes de antemão, a possibilidade de escolha entre estarem juntos ou separados (ALTMANN, 1999, p.176).

Cabe ao professor de educação física o reconhecimento de que a escola é um local evidente da construção social do masculino e feminino. As práticas em que há separação dos sexos formando indivíduos discriminantes de si mesmos devem ser modificadas e substituídas por aquelas não excludentes, que possibilitem formas de diminuir e até mesmo acabar com preconceitos e discriminações ainda muito presentes. É preciso valorizar as práticas proponentes do fim do sexismo no esporte e acabar com ocorrências como a narrada por uma das acadêmicas entrevistadas. Disse ela que tentou iniciar o futsal feminino em algumas escolas, mas o que encontrou foi o "desinteresse total" (Acadêmica A). Quando se falava em futsal feminino, várias diretoras e coordenadoras colocavam empecilhos a sua prática. Poucas escolas desenvolvem treinamentos de futsal feminino sistematizados.

O futebol tornou-se um dos esportes mais populares no mundo. Em praticamente todos os países ele é praticado e possui ligas e confederações. Um dos eventos esportivos mais lucrativos é a Copa do Mundo, divulgada em rede internacional. Em qualquer lugar, independente das condições, o futebol é praticado. Em gramados, parques, ruas estreitas, terrenos baldios, quintais, em qualquer pequeno espaço, crianças e adultos criativamente se divertem com o futebol. Entretanto, não há dúvida que continua sendo um evento predominantemente masculino, em que os principais agentes são homens - os jogadores, o juiz, os técnicos - ou homens estão ali em maioria - os jornalis- 
tas e os espectadores no estádio (HARGREAVES, 1994; RIAL, 2002). A baixa visibilidade das mulheres contribui para a pouca memória social sobre a presença feminina nos campos de futebol.

Ao entrar nos campos, as mulheres impuseram ao mundo masculino do futebol momentos de rara igualdade de papéis, proporcionados pela técnica e pela ginga, porquanto, esses fatores independem de sexo. Em relação a esse aspecto, uma das acadêmicas, quando questionada quanto ao que os garotos pensavam das meninas estarem jogando futsal, respondeu: "Onde eu comecei a treinar tinha meninos que treinavam depois que a gente... Eles sempre ficavam assistindo, e queriam jogar com a gente. Mas na escola, a gente escutava alguns meninos falando que as meninas que jogavam pareciam homens, mas a maioria dos garotos que conheci nunca falaram nada a respeito disso, achavam normal. Mas quando jogávamos com meninos, às vezes surgiam alguns comentários do tipo: 'Ela joga meIhor que homem'"(Acadêmica B). Essa afirmação nos remete a formas de preconceitos que sobrepõem às características meramente físicas; ao considerar a mulher melhor que o homem, isso feriria o homem, ou melhor, sua suposta superioridade nos esportes.
Observamos também na fala de uma acadêmica entrevistada o discurso sobre a falta de apoio de seus familiares na sua escolha pelo futsal como prática esportiva: "Meus pais nunca me apoiaram, pra você ter uma ideia meu pai nunca me viu jogar, muito menos minha mãe... meu avô sim, esse sempre me apoiou. Meus pais diziam que era bobagem e perda de tempo e que não dava futuro jogar futsal... às vezes eu chegava machucada em casa e mancando e fingia que estava tudo bem, eles nunca podiam me ver mancando. Vinham também com discursos machistas, como futebol é coisa de homem" (Acadêmica A). Sobre o mesmo aspecto, outra acadêmica respondeu: "Meus pais sempre me apoiaram... Nunca tive problema com eles... Sempre me incentivaram, me levavam aos jogos, treinos e sempre que podiam iam assistir" (Acadêmica B). Dessas duas afirmações, a primeira mostra como a prática do futsal era e é reprimida, também na educação familiar; a segunda já apresenta perspectivas de mudanças.

Nas falas de algumas alunas que jogam há pouco tempo, encontramos uma menor resistência dos familiares: "eles me apoiam, mas não gostam porque acham que é um esporte de meninos não meninas" (Jogadora 1);"me apoiam apesar de não gostarem muito por- 
que há mais garotos que garotas. Reagiram normais, mas duvidando da minha capacidade pelo fato de ser menina" (Jogadora 7); "minha mãe até aceitava e achava legal, mas meu pai criticava e achava que era coisa de homem" (Jogadora 8); "Eles achavam que era só para homens, mas quando descobriram que tinha mais mulheres jogando não falaram mais nada" (Jogadora 15). Observa-se nessas falas que o futebol ainda é associado à masculinização das meninas, ainda há muita resistência à participação feminina, embora algumas falas apontem flexibilidade e tolerância.

Além disso, ao longo da história do esporte, foram e são distintos os incentivos, o apoio e a visibilidade para a prática esportiva, comparandose homens e mulheres, seja no âmbito da participação, gestão ou administração. As mulheres participam dos fenômenos esportivos atualmente muito mais que há algumas décadas, e estão presentes em várias modalidades esportivas, porém, ainda se percebem, na prática esportiva atual, reflexos dos constructos e perpetuação das crenças da superioridade masculina e a inferioridade feminina (HARGREAVES, 1994).

Apesar da presença feminina sempre crescente na área esportiva, a situação atual das mulheres tem que ser avaliada com cautela, pois mesmo que a participação delas seja significativa, ainda é consideravelmente menor do que a dos homens (GOELLNER, 2005a). Tal como afirma Hargreaves (1994), tem sido extremamente difícil ultrapassar as tradicionais premissas de que as diferenças entre os sexos são fundamentalmente biológicas e não culturais. Assim, no desporto, tal como noutras áreas da vida, algumas representações convencionais e estereotipadas de feminilidade fazem parte de uma estrutura ideológica de poder que limita severamente a autonomia feminina.

A mulher, ao praticar o futebol, por vezes, é representada como masculinizada, sofrendo preconceitos decorrentes de uma visão que dita um modo dominante de feminilidade e beleza. Reis \& Votre (apud VOTRE, 1996, p.80) abordam o assunto, quando relatam que:

O futebol, no Brasil, vem acumulando longa história de exclusão da mulher e de produção de estereótipos sexistas relacionados às contratentativas femininas de inserir-se nele, pois segundo as crenças sociais, o futebol é um esporte que exige resistência viril e músculos fortes, que sem dúvida, demonstram um estereótipo atribuído ao jogador de futebol.

No início do século XX, o fortalecimento do corpo feminino 
através dos exercícios físicos era visto como uma maneira de preparar as mulheres para sua condição essencial de mães, a de uma prole forte e saudável. Porém, não eram todas as atividades que poderiam se praticadas e recomendadas, e o futebol, com suas características masculinas, era considerado muito violento para a conformação corporal feminina, sendo proibida a sua prática. Na década de 40 , o futebol feminino praticamente foi erradicado, proibido, inclusive, no Brasil sob a alegação de provocar prejuízos à saúde da mulher. Dessa forma, até pelo menos a década de 60 , somente vedetes, modelos e atrizes simulavam jogos de futebol. E ainda existe um modelo padronizado de como devem ser as mulheres no que se refere ao padrão de feminilidade. $E$ as mulheres que não se adequam a esse padrão são taxadas de masculinas, sapatão, machorra, etc. (COSTA e RIBEIRO, 2008). Nesse sentido:

Além do medo de que a participação das mulheres em atividades esportivas pudesse desonrá-las havia, ainda, outra preocupação: seu sucesso nestas práticas poderia infringir as leis da natureza, pois, ao mostrarem-se mais fortes do que se supunha, seria fissurado o discurso das diferenças naturais cuja base estava assentada na sobrepujança física de um sexo sobre outro (GOELLNER, 2005b, p.145).

A Legislação contribuiu muito para exclusão das mulheres em atividades desportivas. Já em 1941 se estabeleceu que "Às muIheres não se permitirá a prática de desportos incompatíveis com as condições de sua natureza [...]" (CASTELLANI FILHO, 1994, p.61). Em 1965, reafirma tais disposições: “Não é permitida a prática de lutas de qualquer natureza, futebol, futebol de salão, futebol de praia, pólo aquático, pólo, rúgbi, halterofilismo e baseball" (CASTELLANI FILHO, 1994, p. 63). Em 31 de dezembro de 1979, o CND (Conselho Nacional de Desportos), baixando instruções para a prática de desportos pelas mulheres: Às mulheres se permitirá a prática de desportos na forma, modalidades e condições estabelecidas pelas entidades internacionais dirigentes de cada desporto, inclusive em competições, observado o disposto na presente deliberação (CASTELLANI FILHO, 1994, p.62). Somente em 11 de abril de 1983 as mulheres conseguem a legalização da prática do futebol pela deliberação $n^{\circ} 01 / 83$ do $C N D$, que reconhece o crescente interesse das mulheres pela modalidade, não apenas no Brasil como em todo o mundo. Resolve que o 
futebol feminino poderá ser praticado nos Estados, nos Municípios, no Distrito Federal e nos Territórios, sob a direção das Federações e Ligas do desporto comunitário, cabendo à Confederação Brasileira de Futebol a direção no âmbito nacional.

Conforme Goellner (2001, p.46), "o temor que a mulher rompa algumas barreiras que delimitam as diferenças culturalmente construídas para cada sexo torna imperiosa a sua feminização, caso contrário, diz o discurso dominante, ela estará se masculinizando". As dificuldades encontradas pelo futebol feminino estão diretamente ligadas às diferenças dos sexos, pois o corpo feminino acaba sendo culturalmente inadequado para a prática futebolística. Em contrapartida, garotas que se aproximam desta prática se distanciam de um ideal de corpo feminino, sendo muitas vezes questionadas sobre sua sexualidade.

As respostas das meninas foram bem enfáticas quanto ao tema do preconceito e da discriminação por jogarem futsal: "falam que não sabemos jogar" (Jogadora 1); "sempre sofro preconceitos, às vezes as meninas falam que pareço moleque" (Jogadora 4); "algumas pessoas nos chamam de macho-fêmea e dizem que futsal é coisa de menino, não menina"(Jogadora 6); "às vezes, eles falam que meninas não sabem jogar bola, só canelar"(Jogadora 7); "eles falam que você é menina e isso é coisa de menino, Maria chuteira, Maria moleque, etc. mas não ligo e continuo jogando" (Jogadora 12); "eles discriminam falando que quem joga bola é homem, querendo dizer que somos 'lésbicas', mas não ligo mais" (Jogadora 14). Poucas entrevistadas afirmaram não ter sido vítima de algum tipo de preconceito ou discriminação. Entretanto, essas afirmações confirmam o que os teóricos afirmaram até aqui - mulheres que optam pela prática do futsal, em muitos casos, são questionadas quanto a sua sexualidade. A acadêmica questionada sobre o assunto relatou: "Uma vez na escola, ensino médio, estava jogando com meninos e eu ouvi comentários da funcionária da escola [...] ah, comentários preconceituosos do tipo [...] ah comentários do tipo [...] ela é sapatão [...] odeio essa palavra" (Acadêmica A). Outra acadêmica respondeu: "Quando eu jogava futsal, algumas vezes algumas pessoas falavam que eu tinha jeito de menino, que eu parecia menino" (Acadêmica B). Percebemos assim que ainda há muitas conquistas a realizarem-se, embora já exista um espaço conquistado pelas muIheres. É tarefa da educação física quebrar o estigma que aprisiona as jogadoras de futebol em representações depreciativas, como a de "Maria chuteira". 
Os desafios a serem vencidos pelas mulheres estão também em aspectos técnicos: os campeonatos regionais são poucos, não há evento de porte nacional, nem número considerável de mulheres nas comissões técnicas dos clubes de futebol feminino, nem nas entidades que regem este esporte. Além, evidentemente, dos vários preconceitos e estereótipos que ainda cercam a prática da modalidade, tais como a associação de sua imagem à homossexualidade ou os perigos de choque nos órgãos de função reprodutiva (GOELLNER, 2005a).

O esporte tem procurado sua visibilidade, porém, como afirmam as acadêmicas "o que mais tem é preconceito [...] principalmente no futebol. Quando eu estava indo nas escolas pra divulgar o meu projeto de futsal, conversei com algumas mães que as filhas estavam interessadas em treinar, e o que eu mais ouvi é que futsal era coisa pra moleque, por isso não apoiavam suas filhas, acho que por isso não tem muitas meninas inscritas no projeto" (Acadêmica A). Os preconceitos, a falta de incentivos e a invisibilidade prejudicam a prática dessa modalidade, bem como sua inserção na mídia.

\section{Considerações finais}

É evidente que a participação das mulheres ainda é significativa- mente menor que a dos homens no mundo esportivo e de visibilidade midiática, inclusive pela falta de investimentos e de políticas de inclusão das mulheres no esporte. Cabe aos professores de educação física e à escola atuarem para a mudança nas formas de abordar certos temas, como os de gênero, tão polêmicos e confusos para muitos profissionais, buscando na sua intervenção maneiras de minimizar as práticas excludentes, possibilitando a equidade desejada entre os gêneros.

Nesse sentido, torna-se imperativa a mudança nas práticas educativas dentro das escolas, para que possam propor o fim do sexismo no esporte. O esporte muitas vezes se traduz como um importante elemento de visibilidade da mulher na sociedade e no espaço público; muitos nomes que se destacaram como talentos esportivos são resultantes de lutas ao longo dos anos por conquistas nesse espaço marcadamente masculino. Porém, as políticas de incentivo ao esporte feminino ainda são menores que para o masculino, sendo mais evidente no caso do futebol. $\mathrm{E}$ há um mundo a se fazer nesses aspctos, em se tratando de Brasil.

Como afirma Goellner (2005b), em um país como o Brasil, onde o futebol incorpora-se discursivamente à identidade nacional, faz-se extremamente necessário pensar o 
quanto este é para as mulheres um espaço a ser conquistado, mas, sobretudo, é preciso ressignificar alguns de seus sentidos, impondo e afirmando que ele também lhes pertence, como um espaço de liberdade a todos.

Há muito a ser feito, e propõe-se nesse trabalho que as práticas sejam ressignificadas, e que seu início se dê nas instituições de ensino e nas políticas públicas de incentivo, pois se em um universo onde há a formação do cidadão as práticas permanecem excludentes, não haverá maneiras de modificação da sociedade na qual estamos inseridos. Espera-se que pensemos sobre nossas atitudes como educadores, e que reflitamos, buscando ao longo de toda a formação maneiras de conduzir o processo de ensino-aprendizagem, incluindo nele discussões que possam reduzir/minimizar, concorrendo para resolver, os problemas oriundos do sexismo dentro das escolas, que são instituições de grande importância social.

\section{Referências}

ALTMANN, Helena. Rompendo fronteiras de gênero: marias (e) homens na educação física. Revista Brasileira de Ciências do Esporte, v.21, p. 112-117; 175-176, 1999.
CASTELLANI FILHO, L. Educação física na Brasil: a história que não se conta. 4.ed. Campinas: Papirus, 1994.

COSTA, Maria Regina Ferreira da. RIBEIRO, Gabriela Chicuta. As mulheres e o futebol: relação diferenciada? In: Fazendo Gênero - Corpo, Violência e Poder, 8., 2008. Florianópolis. 1 CD-ROM.

DARIDO, S. C. Futebol feminino no Brasil: do seu início à prática pedagógica. Motriz, Rio Claro, v.8, n.02, p.43-49, abr/ago 2002.

GOELLNER, Silvana Vilodre. A educação física e a construção do corpo da mulher: imagem de feminilidade. Revista Motrivivência, Florianópolis: UFSC, ano XII, n.16, p. 35-52, mar. 2001. . Mulher e esporte no Brasil: entre incentivos e interdições na História. Revista pensar a prática, Porto Alegre, v.8, n.01, p.85-100, jan/jun. 2005a.

. Mulheres e futebol no Brasil: entre sombras e visibilidades. Rev. bras. Educ. Fís. Esp., São Paulo, v.19, n.2, p.143-51, abr/ jun. $2005 b$.

. Feminismos, mulheres e esportes: questões epistemológicas sobre o fazer historiográfico. Movimento, Porto Alegre, v.13, n. 02, p.171196, maio/agosto de 2007a. 
- Mulheres, memórias e histórias: reflexões sobre o fazer historiográfico. In: Goellner, Silvana V; JAEGER, Angelita A.. (Org.). Garimpando Memórias: esporte, Educação Física, lazer e dança. 1 ed. Porto Alegre: Editora da UFRGS, 2007b, v. 1, p. 13-26.

LOURO, Guacira Lopes. Gênero, história e educação: construção e desconstrução. Educação \& realidade, Porto Alegre, v.2, n.20, p.101-132, jul/dez. 1995. . Gênero, sexualidade e educação: uma perspectiva pósestruturalista. 9 ed. Petrópolis: Vozes, 2007a.

- Currículo, gênero e sexualidade: o "normal", o "diferente" e o "excêntrico". LOURO, G. L., GOELLNER, S. V. (org.). Corpo, gênero e sexualidade: um debate contemporâneo na educação. Petrópolis, RJ: Vozes, 2007b. p.41-52.

HARGREAVES, J. Sporting females:

Critical issues in the history and sociology of women's sports. London: Routledge, 1994.

LESSA, Patrícia. Mulheres, corpo

e esportes em uma perspectiva feminista. Revista Motrivivência. Florianópolis: UFSC, ano XVII, n.24, p.157-172, jun 2005.

MEYER, Dagmar. Gênero e educação: teoria e política. In:
LOURO, Guacira; NECKEL, Jane F.; GOELLNER, Silvana V. (Orgs.). Corpo, gênero e sexualidade: um debate contemporâneo na educação. Petrópolis: Vozes, 2007. p. 9-27.

PEREIRA, S. A. M. O sexismo nas aulas de educação física: uma analise dos desenhos infantis e dos estereótipos de gênero nos jogos e brincadeiras. Rio de Janeiro, Universidade Gama Filho, 2004, 182 p. Tese (doutorado) - Programa de PósGraduação em Educação Física, Universidade Gama Filho, Rio de Janeiro, 2004.

RIAL, Carmen. Televisão, futebol e novos ícones planetários: aliança consagrada nas copas do mundo. Motrivivência, ano XIII, n.18, p. 15-31, mar. 2002.

SCOTT, Joan. Desconstructing equality-versus-difference: Or the uses of poststructuralist theoryvfor feminism. Feminism Studies, v.14, n.1, p.33-50, 1988.

SIMÕES, Renata Duarte. Gênero na Educação Física: a emergência de um conceito. In: XIII CONBRACE - Congresso Brasileiro de Ciências do Esporte, 2003, Caxambu MG. Anais do XIII CONBRACE, 2003.

SWAIN, Tania Navarro. Quem tem medo de Foucault? Feminismo, corpo e sexualidade. Disponível 
em: < <http://www.unb.br/ $\mathrm{fe} /$ tef/filoesco/foucault/ $>>$. Acesso em: 25 abr.2009.

TOJAL, Marcyette Caldas. Corpo de mulher e poder: relações de gênero. Lato \& Sensu, Belém, v.4, n.1, p.1-8, out 2003.

VOTRE, S. A representação social das mulheres na educação física e no esporte. Rio de Janeiro: editora Central da Universidade Gama Filho, 1996.

Recebido: 30/agosto/2009 Aprovado: 16/outubro/2009 